\title{
A microdeletion at Xq22.2 implicates a glycine receptor GLRA4 involved in intellectual disability, behavioral problems and craniofacial anomalies
}

\author{
Jonathan D. J. Labonne ${ }^{1,2}$, Tyler D. Graves ${ }^{1}$, Yiping Shen ${ }^{3}$, Julie R. Jones ${ }^{4}$, II-Keun Kong ${ }^{5}$, \\ Lawrence C. Layman ${ }^{1,2,6}$ and Hyung-Goo Kim ${ }^{1,2^{*}}$
}

\begin{abstract}
Background: Among the 21 annotated genes at Xq22.2, PLP1 is the only known gene involved in Xq22.2 microdeletion and microduplication syndromes with intellectual disability. Using an atypical microdeletion, which does not encompass PLP1, we implicate a novel gene GLRA4 involved in intellectual disability, behavioral problems and craniofacial anomalies.

Case presentation: We report a female patient (DGDP084) with a de novo Xq22.2 microdeletion of at least $110 \mathrm{~kb}$ presenting with intellectual disability, motor delay, behavioral problems and craniofacial anomalies. While her phenotypic features such as cognitive impairment and motor delay show overlap with Pelizaeus-Merzbacher disease (PMD) caused by PLP1 mutations at Xq22.2, this gene is not included in our patient's microdeletion and is not dysregulated by a position effect. Because the microdeletion encompasses only three genes, GLRA4, MORF4L2 and TCEAL1, we investigated their expression levels in various tissues by RT-qPCR and found that all three genes were highly expressed in whole human brain, fetal brain, cerebellum and hippocampus. When we examined the transcript levels of GLRA4, MORF4L2 as well as TCEAL1 in DGDP084's family, however, only GLRA4 transcripts were reduced in the female patient compared to her healthy mother. This suggests that GLRA4 is the plausible candidate gene for cognitive impairment, behavioral problems and craniofacial anomalies observed in DGDP084. Importantly, glycine receptors mediate inhibitory synaptic transmission in the brain stem as well as the spinal cord, and are known to be involved in syndromic intellectual disability.
\end{abstract}

Conclusion: We hypothesize that GLRA4 is involved in intellectual disability, behavioral problems and craniofacial anomalies as the second gene identified for X-linked syndromic intellectual disability at Xq22.2. Additional point mutations or intragenic deletions of GLRA4 as well as functional studies are needed to further validate our hypothesis.

Keywords: GLRA4, Xq22.2, Pseudogene, Intellectual disability, Behavioral problems, Craniofacial anomalies, Microdeletion

\section{Background}

Intellectual disability (ID) is a genetically heterogeneous condition with $2 \%$ of the population estimated to be impacted by this disorder $[1,2]$. Such impairment of cognitive functions places a high burden on families as well as society making ID an important problem in medicine

\footnotetext{
* Correspondence: hkim@augusta.edu

'Department of Obstetrics \& Gynecology, Section of Reproductive Endocrinology, Infertility \& Genetics, Medical College of Georgia, Augusta University, 1120 15th Street, Augusta, GA 30912, USA

${ }^{2}$ Department of Neuroscience and Regenerative Medicine, Medical College of Georgia, Augusta University, 1120 15th Street, Augusta, GA 30912, USA Full list of author information is available at the end of the article
}

[3]. Notably, X-linked intellectual disability (XLID) is approximately 4 times more prevalent than autosomal forms [4]. Of the $\sim 1,098$ genes residing on the $\mathrm{X}$ chromosome [5], a large number play a role in neurological functions $[4,6]$, and some of these genes are highly expressed in the brain [7]. More than 100 ID genes residing on the $\mathrm{X}$-chromosome have been identified, and it is thought that more XLID genes are yet to be discovered, particularly in X-linked families where the genes map to new loci $[2,8-10]$.

Being approximately $1 \mathrm{Mb}$ in size, chromosomal segment Xq22.2 contains at least 21 annotated genes 
including TCEAL1 (MIM 300237), MORF4L2 (MIM 300409), PLP1 (MIM 300401) and an apparent pseudogene (GLRA4) [11]. Among these genes, PLP1 mutations have been previously shown to be associated with the neurological disorder Pelizaeus-Merzbacher disease (MIM 312080) characterized by intellectual disability, nystagmus, ataxia, spasticity, and microcephaly. Brain MRI revealed macrogyria, dysmyelination, and increased paramagnetic signal which is indicative of iron deposition $[12,13]$. Furthermore, PLP1 is also involved in Xq22.2 microdeletion and microduplication syndromes [8].

The apparent human pseudogene glycine receptor $\alpha 4$ subunit (GLRA4) lacks the 4th transmembrane domain (TM4) located at the C-terminal end of the protein [11, $14,15]$. Glycine receptors (GLRs) are important in mediating inhibitory neurotransmission in the brain $[14,16$, 17]. However, the role played by GLRA4 in humans is unclear because the absence of the TM4 domain is expected to be damaging to GLRA4 protein function [13]. Pseudogenes have been long considered as silent relics residing in the genome as neutral sequences with no biological roles $[18,19]$. However, over the past decade, evidence is mounting that pseudogenes have biological functions and may play a role in health and disease [19-22]. For instance, post-transcriptional silencing of HMGA1 (MIM 600701) by its pseudogene (HMGA1-p) leads to insulin resistance and type 2 diabetes [22]. Similarly, pseudogene PTENP1 has been shown to exert a growth-suppressive role by regulating the transcript levels of the tumor suppressor gene PTEN (MIM 601728) [21].

Here, we report an 11-year-old female patient presenting with intellectual disability, behavioral problems and craniofacial anomalies. We performed microarray and identified an apparent $\sim 105 \mathrm{~Kb}$ microdeletion at Xq22.2. The genomic deletion encompasses the genes TCEAL1 (MIM 300237), MORF4L2 (MIM 300409) and an apparent pseudogene GLRA4. We performed qPCR to refine the locations of the proximal as well as the distal deletion breakpoints. The myelin proteolipid protein-coding gene (PLP1) resides $\sim 46 \mathrm{~kb}$ distal to the microdeletion. We examined the transcript levels of GLRA4, TCEAL1, MORF4L2 as well as PLP1 (MIM 300401) in the patient and family members. The protein levels of PLP1 were also examined by Western blot to determine whether PLP1 is dysregulated by a position effect. We assayed the level of transcripts of GLRA4, MORF4L2, and TCEAL1 in the brain and other tissues. We hypothesize that GLRA4 is a novel candidate gene for XLID and is likely involved in the clinical features observed in our patient including cognitive impairment, behavioral problems and speech delay.

\section{Case presentation}

The proband (DGDP084) is an 11-year-old girl born after normal pregnancy and delivery. At birth, she weighed $2.83 \mathrm{~kg}$. She passed her neonatal hearing screen test and did not require admission to the special care unit. At around 8 weeks, the infant started manifesting nystagmus. An MRI turned out to be normal. At 8 months, her parents started to have concerns about her motor skills. She was not yet sitting or weight bearing. She continued to display jerky eye movement and showed some reluctance to elevate her eyes. Upon examination at 9 months, development of her gross motor skills was found to be delayed. At 15 months, her gross motor skills were determined to be at the 9month-level. Her parents also noted that she was slow to develop movement patterns, particularly involving rotation. At that time, the infant was described as a happy, smiling little girl.

When examined at 20 months, she was still showing developmental delay. She was not yet crawling, and used a lot of jargon with no clear words. She was able to roll and enjoyed clapping and waving goodbye. At 2 years and 1 month she had a brief generalized tonic clonic seizure associated with fever. As a 2 year and 3-month old girl, she was able to recognize her name and understand the names of familiar adults. She was crawling efficiently and enjoyed turning pages of her books. She was able to bring a spoon to her mouth, but required her parents' assistance for loading. A thyroid function test performed at 2 years and 8 months did not detect any abnormalities. Her development at that time was quite significantly delayed in many areas and she was functioning at around the 12-month level. She walked with a wide spaced ataxic gait and displayed some stereotypical hand movements. The girl also had episodes where she would stare and look blankly for approximately $10 \mathrm{~s}$. She displayed some of the physical and behavioral features of Angelman syndrome. She has had extensive testing of genetic changes normally seen in children with Angelman syndrome. This has excluded a maternally inherited deletion, uniparental disomy, $\mathrm{CNV}$ analysis, abnormal methylation at $15 \mathrm{q} 11-\mathrm{q} 13$, or a mutation in $U B E 3 A$ gene as causative. As some children with $M E C P 2$ deletions have an Angelman-like phenotype, gene testing of MECP2 (MIM 300005) was also done, which was also negative. Mowat-Wilson syndrome (MIM 235730), clinically similar to Angelman syndrome, is caused by mutations of SIP1 (aka ZEB2, MIM 605802). Mutation screening of this gene was negative. Although Angelman syndrome patients show specific EEG patterns, an EEG showed no specific or paroxysmal abnormality in DGDP084. This suggests that she was not suffering from Angelman syndrome.

At 3 years and 4 months, the patient had a head circumference at $49.5 \mathrm{~cm}$ (50th centile). She had deep blue, lightly pigmented irides and displayed frontal bossing as well as a flat occiput. The patient also had a prominent chin (Fig. 1a) and displayed fifth finger clinodactyly 
(Fig. 1e and $\mathrm{f}$ ). When she was examined at 4 years-1month, her parents revealed that their daughter's sleep patterns were disturbed. She would wake up in the middle of the night and start banging on her window. At 4 years-7-months, she displayed global developmental delay, hypermetropic astigmatism, and minor jerky eye movement. Her height was at the 25th centile and weight on the 75th centile. At that time, she was also enrolled in special schooling. She had several episodes of significant abdominal pain associated with constipation and was being treated with Movicol.

As a 5-year-old girl, the patient displayed significant learning difficulties. She was also experiencing intermittent episodes of distress during which she was making straining noises. These episodes occurred approximately every month or two, lasting up to one week. During those episodes, she often sat in an unusual position with her legs folded underneath, her head held back and in a dream-like state. She was also diagnosed with glycosuria. At that time, the patient had a head circumference of $55.5 \mathrm{~cm}$ (between the 9th and 25th centile), weighed $19.4 \mathrm{~kg}$ (50th centile), and her height was at $107.4 \mathrm{~cm}$ (25th centile). Her sleep patterns were still variable despite being treated with Melatonin. She continued to have an ataxic wide-based gait and displayed stereotypic arm movements with hand flapping. She also had a tendency to walk in a side-to-side stepping

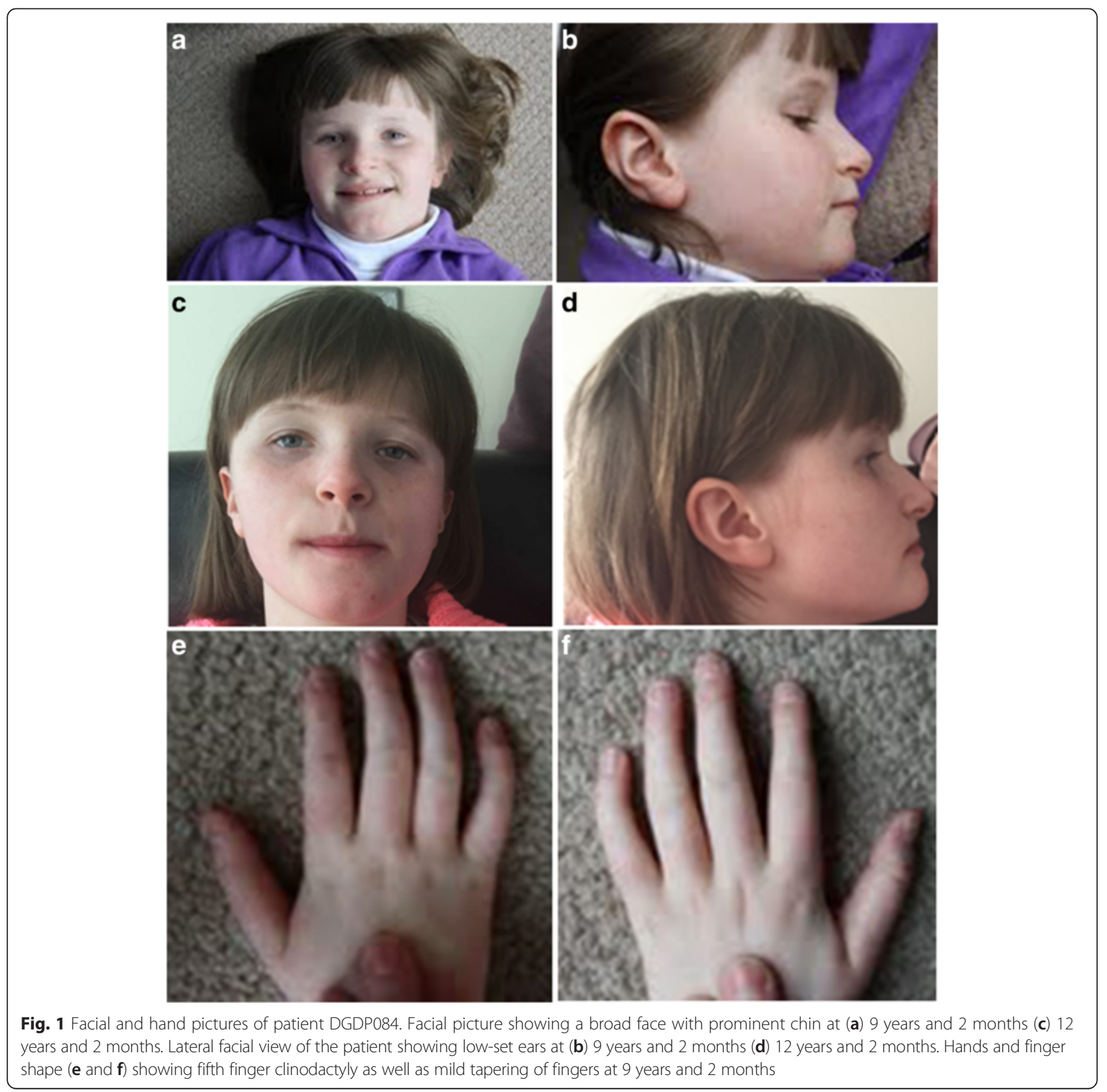


instead of forward stepping. Microarray analysis revealed a deletion at Xq22.2.

When examined as a 6-year-old girl, she weighed $18.7 \mathrm{~kg}$ (9th-25th centile), and her height was $110.1 \mathrm{~cm}$ (9th-25th centile). She displayed poor coordination, and her speech had not yet developed. The girl was diagnosed with Type 1 diabetes, and a heart murmur was also detected. She continued to have problems with constipation and was taking Chloral hydrate. Her parents mentioned that her problematic sleep patterns were becoming a concern as the banging noises were disturbing neighbors. The repeated banging also left marks on her wrist, and she was also eating nonfood items. She was dependent on her parents for all her personal care and was also enrolled in occupational therapy. While still a 6-year old girl, she had chicken pox, which was mild in nature. She continued to have unsettled nights as a 7-year-old girl and at that time the abdominal discomfort was thought to be presumably responsible. A summary of DGDP084 clinical features is provided in Table 1.

Family history is unremarkable except for the father, paternal grandmother and a maternal cousin. The patient's father has Type I diabetes, while the maternal cousin displays cerebral palsy. The paternal grandmother had a number of stillborn babies.

\section{Methods}

Lymphoblastoid cell lines were made from blood samples obtained from patient DGDP084 and her parents using a density gradient centrifugation method following Nishimoto et al. [23]. Genomic DNA was isolated from blood samples using a standard phenol-chloroform protocol with minor modifications. The extracted genomic DNA from the patient's blood was examined on a comparative genomic hybridization array $(\mathrm{aCGH})$ to detect pathogenic copy number variations (CNVs) as described [24]. The X chromosome inactivation (XCI) pattern using genomic DNA from patient DGDP084 was determined by PCR analysis of a polymorphic CAG repeat in the first exon of the androgen receptor $(A R)$ gene. Methylation of sites close to this short tandem repeat has been demonstrated to correlate with $\mathrm{X}$ chromosome inactivation [25]. In this assay, amplification of the $A R$ gene both before and after digestion with the methylation-sensitive HpaII restriction enzyme was used to determine the methylation status of the maternal and paternal X chromosome. XCI degree threshold patterns are classified as random $(\mathrm{XCI}<80 \%)$, moderately skewed $(80 \% \leq \mathrm{XCI} \leq 90 \%)$, and highly skewed (>90\%) [26].

Primers targeting the putative proximal and distal deletion breakpoints at Xq22.2 were designed for qPCR. We also made primers against exonic sequences of GLRA4, TCEAL1, MORF4L2, and PLP1 for qPCR as well as RTqPCR (Additional file 1: Table S1). Total RNA was extracted from cell lines using the RNeasy Plus Mini kit (Qiagen) following the manufacturer's instructions. RTqPCR was performed using total RNA (Clontech) from whole human brain, fetal brain, cerebellum, cerebral cortex, hippocampus, kidney, liver, lung, heart and skeletal muscle. cDNA was synthesized from $1 \mu \mathrm{g}$ of total RNA using the RevertAid First cDNA Synthesis Kit (Thermo Scientific). Real-Time PCR was carried out using $2 \mu \mathrm{l}$ cDNA, $2.5 \mu \mathrm{M}$ primer and $10 \mu \mathrm{l}$ FastStart DNA Green Master (Roche) in a $20 \mu \mathrm{l}$ reaction volume. Samples were run in triplicates and standard errors were calculated from 2-3 independent experiments. The $\Delta \Delta \mathrm{ct}$ method was used to determine copy number of the loci of interest as well as relative transcript levels of genes of interests. The beta-2-microglobulin (MIM 109700) gene was used for

Table 1 Clinical features of DGDP084 compared with other patients having small-sized microdeletions within the Xq22.2 interval

\begin{tabular}{|c|c|c|c|c|c|c|c|}
\hline \multirow[t]{3}{*}{ Clinical features } & \multirow[t]{2}{*}{ DGDP084 } & Yamamoto & Torisu & Inoue 2002 & Inoue 2002 & Inoue 2002 & Matsufuji 2013 \\
\hline & & 2014 Pt5 & 2012 & Pt 1 & Pt 2 & Pt 3 & Pt II-1 \\
\hline & $\mathrm{F}$ & $\mathrm{F}$ & M & M & M & M & M \\
\hline Intellectual disability & + & + & + & + & + & + & + \\
\hline Speech delay & + & + & + & NS & + & + & + \\
\hline Motor delay & + & + & + & + & + & + & + \\
\hline Impaired social skills & + & + & - & NS & + & NS & + \\
\hline Sleep disturbance & + & + & NS & NS & NS & NS & NS \\
\hline Behavioral problems & + & + & NS & NS & NS & NS & NS \\
\hline Seizures & + & - & NS & NS & - & NS & - \\
\hline Craniofacial anomalies & + & + & + & NS & NS & NS & NS \\
\hline Tapering fingers \& clinodactyly & + & - & NS & NS & NS & NS & NS \\
\hline Brain MRI - delayed myelination & - & + & + & + & + & NS & + \\
\hline Cardiac anomalies & + & - & NS & NS & NS & NS & NS \\
\hline Gastrointestinal problems & + & - & NS & NS & NS & + & + \\
\hline
\end{tabular}

NS not stated, Pt patient, $F$ represents female while $M$ denotes male 
data normalization. Numerical means and standard deviations for $\mathrm{qPCR}$ and RT-qPCR are provided in Additional file 1: Table S2 and S3, respectively. Protein was isolated from cell lines derived from patient DGDP084 and family members. Anti-PLP1 antibody (Abcam) targeting amino acids109-128 was used to detect PLP1 protein expression levels. A dilution of 1:1000 was used for the primary antibody, while the secondary anti-rabbit antibody (Thermo Scientific) was diluted 1:1000. Detection was carried out using the Amersham ${ }^{\mathrm{TM}}$ ECL $^{\mathrm{Tm}}$ Western Blotting Analysis System (GE Healthcare).

\section{Results}

Microarray analysis reveals a microdeletion in patient DGDP084 at Xq22.2

A $105 \mathrm{~kb}$ minimal microdeletion at Xq22.2 (chrX: $102,882,657-102,987,229$, hg 19) was detected by microarray analysis with a putative maximal deletion determined to be $\sim 145 \mathrm{~kb}$ (chrX:102,857,905-103,002,957, hg 19). The deleted genomic region contains only three genes namely, MORF4L2, GLRA4, and TCEAL1 (Fig. 2 and Table 2).

\section{Microdeletion occurred as a de novo event}

qPCR assays using genomic DNA and primers targeting GLRA4 confirmed the Xq22.2 microdeletion in female DGDP084 and also revealed that the chromosomal rearrangement occurred as a de novo event. As expected, the patient's healthy mother possesses two copies of GLRA4, while the healthy father has only one copy (Fig. 3a). According to qPCR analysis the size of the microdeletion is at least $110 \mathrm{~kb}$ and does not extend into the proximal genes, TCEAL3 and PLP1. The centromeric deletion breakpoint resides in the intergenic region 1 between TCEAL1 and TCEAL3, while the telomeric breakpoint was found to reside in the intergenic region 2 between GLRA4 and PLP1 (Figs. 2 and 3b).

\section{Transcript levels of GLRA4 are reduced in patient DGDP084}

Analysis of GLRA4 transcript levels by RT-qPCR revealed low GLRA4 expression in DGDP084 girl similar to her healthy father, but much lower than her mother (Fig. 4a). The transcript levels of MORF4L2 in DGDP084 were statistically not different to her parents (Fig. 4b). TCEAL1

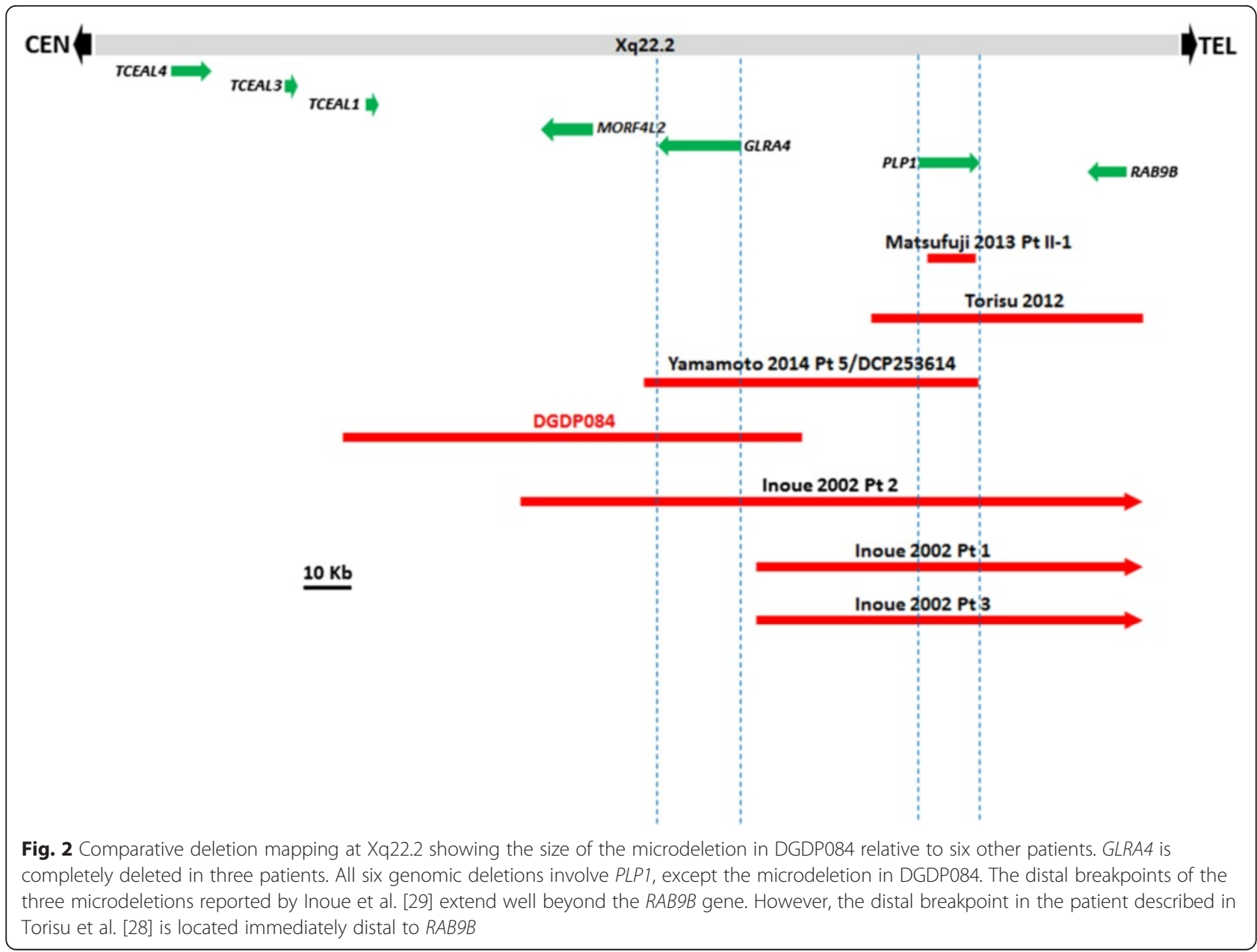


Table 2 Genes deleted in DGDP084

\begin{tabular}{|c|c|c|c|}
\hline Gene & $\begin{array}{l}\text { Gene } \\
\text { symbol }\end{array}$ & OMIM\# & Remarks \\
\hline $\begin{array}{l}\text { Glycine receptor, } \\
\text { alpha } 4 \text { subunit }\end{array}$ & GLRA4 & - & $\begin{array}{l}\text { Glycine receptors mediate } \\
\text { neurotransmission in the } \\
\text { spinal cord and brain stem. } \\
\text { Human GLRA4 is considered } \\
\text { as a pseudogene and has a } \\
\text { stop codon before the } \\
\text { predicted transmembrane } \\
\text { domain (exon 9) }[11,36] \text {. }\end{array}$ \\
\hline $\begin{array}{l}\text { Mortality factor } \\
4 \text { like } 2\end{array}$ & MORF4L2 & 300409 & $\begin{array}{l}\text { May be implicated in cellular } \\
\text { senescence like } 2 \text { [52]. The } \\
\text { mouse homolog (MgrX) is not } \\
\text { essential for growth and } \\
\text { development [37] }\end{array}$ \\
\hline $\begin{array}{l}\text { Transcription } \\
\text { Elongation } \\
\text { Factor A-Like } 1\end{array}$ & TCEAL1 & 300237 & $\begin{array}{l}\text { Nuclear phosphoprotein having } \\
48 \% \text { Elongation homology to } \\
\text { transcription factor SIl factor } \\
\text { A-like-1 [53]. }\end{array}$ \\
\hline
\end{tabular}

transcript level was consistent across all family members (Fig. 4c). The levels of PLP1 transcripts in DGDP084 were statistically not different to her healthy mother (Fig. 4d).

\section{Random X-chromosome inactivation in DGDP084}

$\mathrm{X}$-inactivation studies revealed an inactivation ratio of $77: 23$. Since inactivation ratios of less than $80: 20$ are considered random patterns, this suggests a random inactivation of chromosome $\mathrm{X}$ in this microdeletion female. The X-chromosome with the Xq22.2 microdeletion in DGDP084 is not preferentially inactivated.

\section{GLRA4, MORF4L2 and TCEAL1 are highly expressed in the brain}

Transcripts of GLRA4 were 25 -fold higher in whole human brain relative to lymphocytes. Little or no GLRA4 transcripts were detected in the heart, kidney,

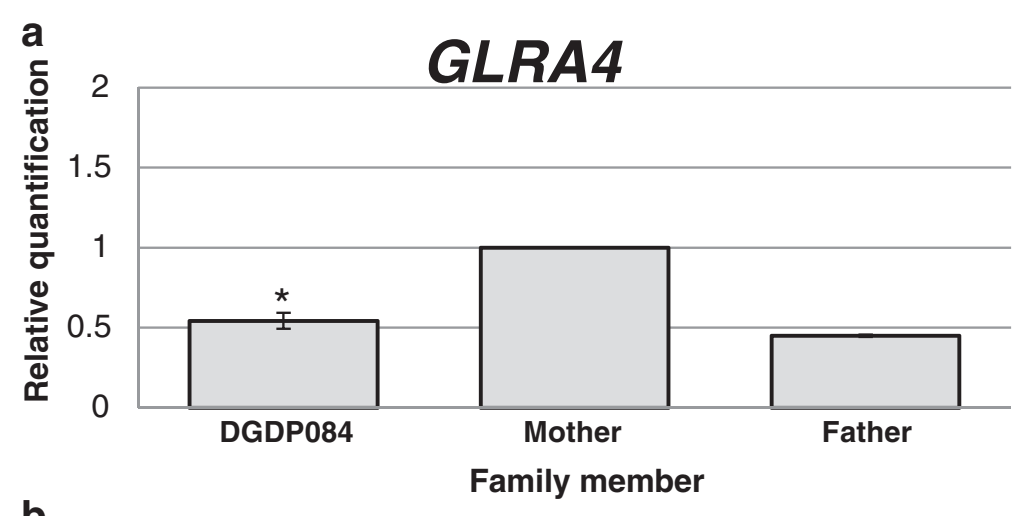

b

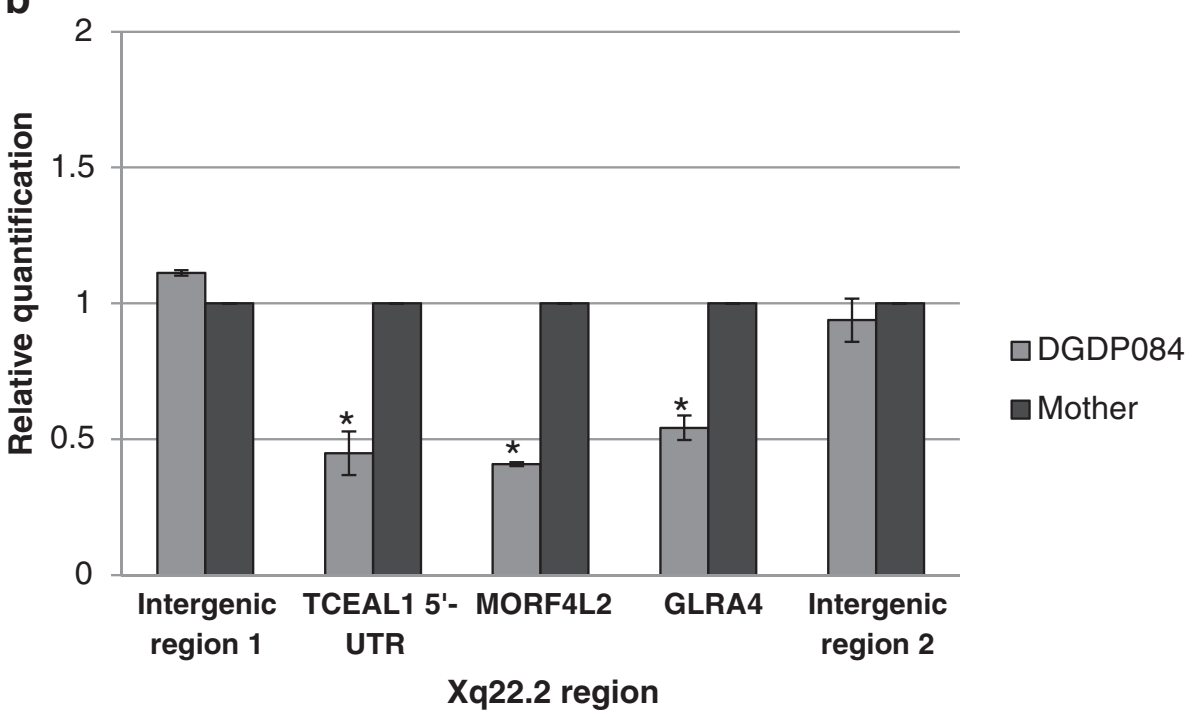

Fig. 3 Refining deletion breakpoints in DGDP084. a qPCR assays confirmed the Xq22.2 microdeletion in DGDP084. GLRA4 copy number in DGDP084 was compared to her mother as a gender control. The patient's mother was normal possessing two copies of GLRA4, while the father and the affected female DGDP084 have only one GLRA4 allele on the chromosome X. b The copy number of genes and loci in DGDP084 at Xq22.2 were compared to her mother. The TCEAL1 gene was found to be completely deleted with the proximal deletion breakpoint lying between TCEAL1 and TCEAL3. The distal deletion breakpoint was located in the non-genic region between GLRA4 and PLP1. Asterisks denote differences that are statistically significant 


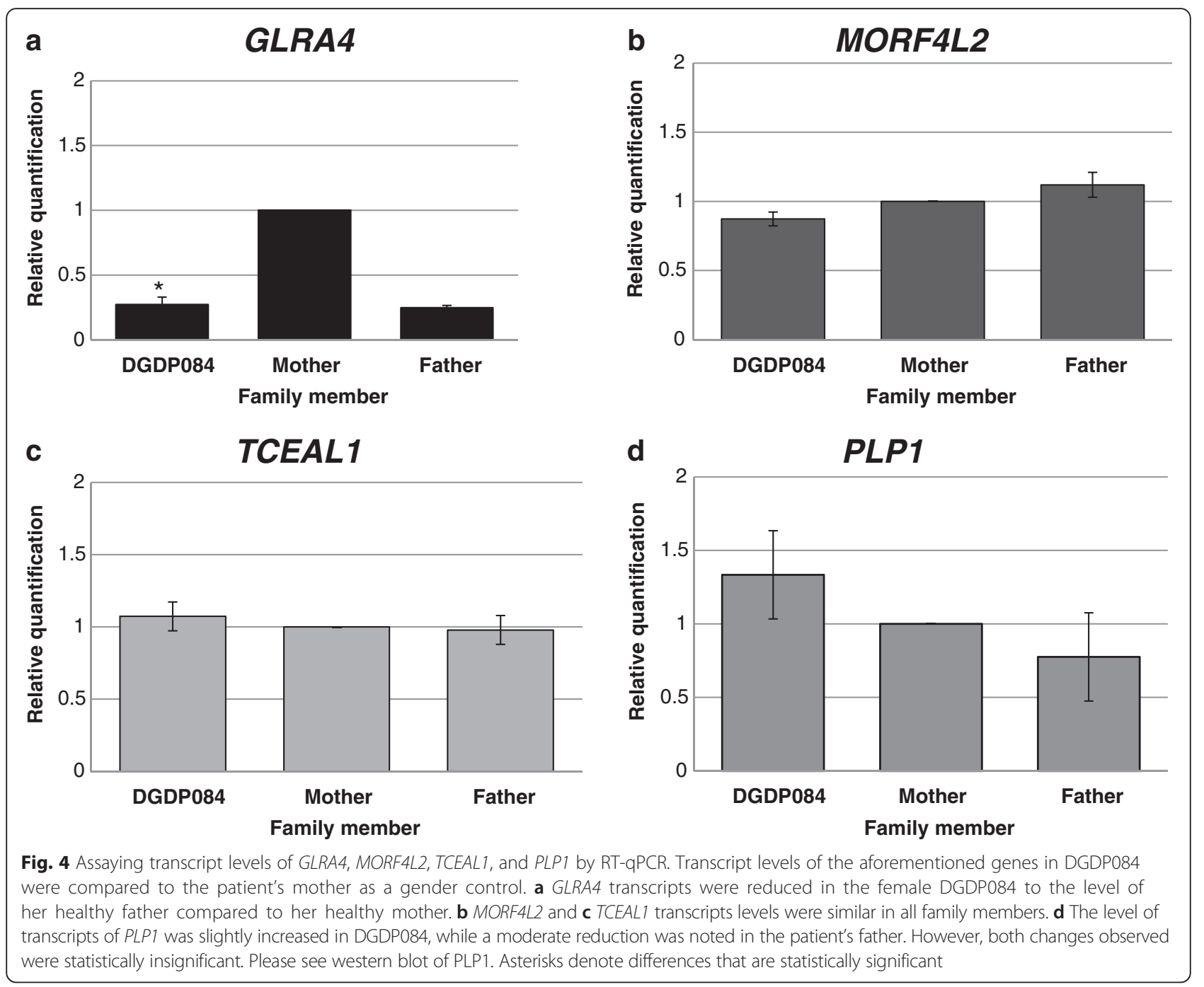

liver, lung, and skeletal muscle (Fig. 5a). The level of MORF4L2 transcripts was $\sim 24$-fold higher in the brain, and 10-fold higher in skeletal muscle relative to lymphocytes (Fig. 5b). Very low levels of MORF4L2 transcripts were detected in other tissues assayed. Transcript levels of TCEAL1 were extremely high in the brain ( 50-fold) compared to lymphocytes (Fig. $5 \mathrm{c}$ ). High levels of TCEAL1 transcripts (20-fold) were also detected in skeletal muscle relative to lymphocytes. Kidney, liver and lung expressed very low levels of TCEAL1 transcripts.

Transcripts of GLRA4, MORF4L2 and TCEAL1 were abundantly expressed in fetal brain, cerebellum, cerebral cortex and hippocampus (Fig. 5d-f). The highest transcript levels were detected in fetal brain where an $~ 60$ fold, 30-fold, 90-fold higher level of transcripts were detected for GLRA4, MORF4L2 and TCEAL1, respectively relative to lymphocytes.
Western blot shows that PLP1 is not dysregulated by position effect

By densitometry, the PLP1 protein was found to be expressed at the same levels in DGDP084, her parents and the two controls as normalized to GAPDH (Fig. 6). No gender difference in PLP1 protein expression was observed across the individuals assayed. We did not detect GLRA4 protein in lymphocytes but low levels were expressed in fibroblasts (data not shown).

\section{Comparative deletion mapping at $\mathrm{Xq} 22.2$}

We performed comparative deletion mapping with DGDP084 and six additional informative microdeletions at Xq22.2 (Fig. 2). Patient II-1 of Matsufuji et al. [27] has a 33-kb microdeletion spanning PLP1 only. The CNV in patient 5 of Yamamoto et al. [8] encompasses GLRA4 and PLP1only, while the microdeletion in the patient of 


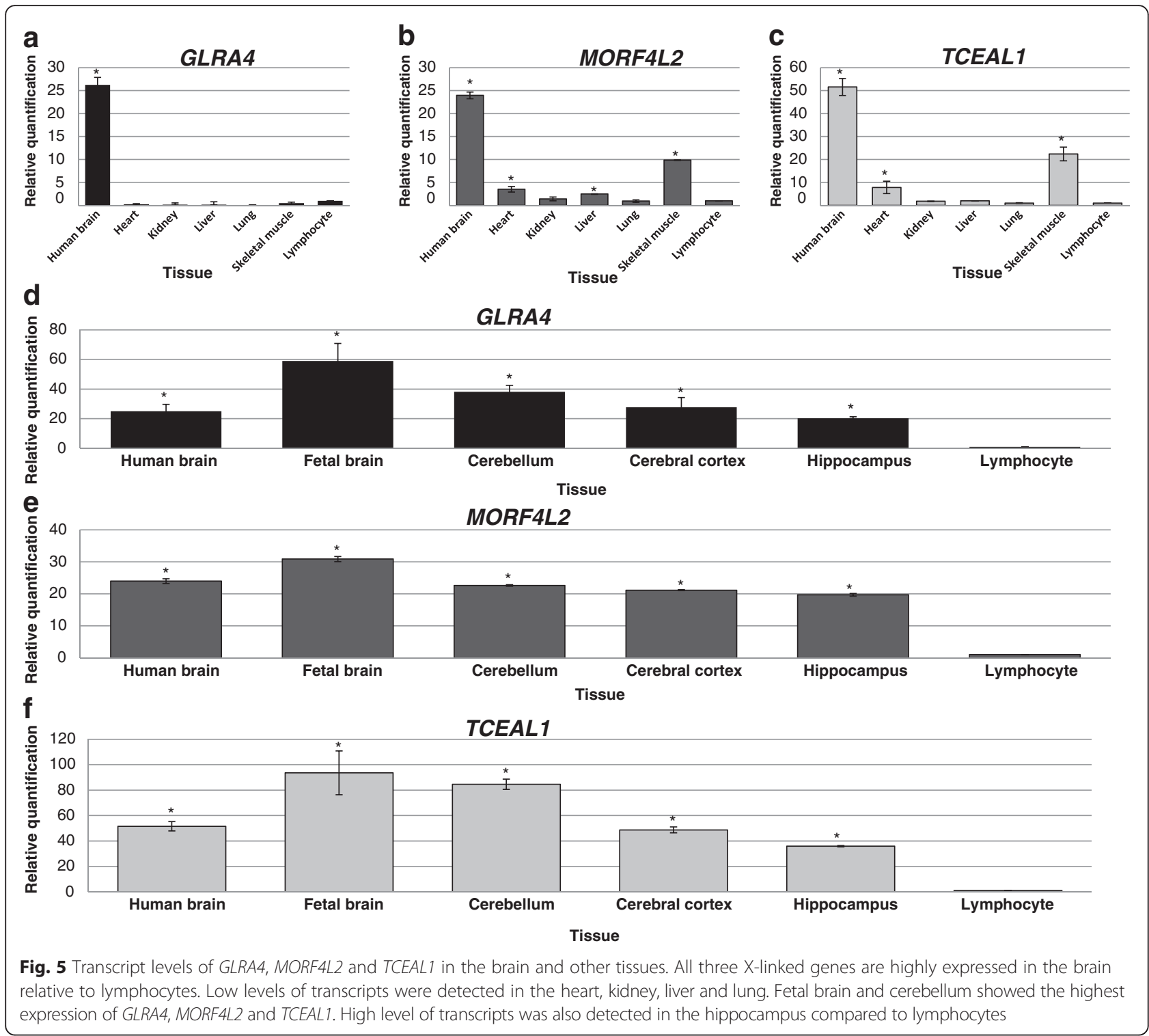

Torisu et al. [28] includes PLP1 and RAB9B only. Patient 2 of Inoue et al. [29] has a microdeletion involving at least MORF4L2, GLRA4, PLP1, RAB1 whereas his patients 1 and 3 of Inoue et al., [29] have CNVs encompassing at least PLP1 and $R A B 9 B$. The deletion breakpoints of the three patients reported in Inoue et al. [29] have not been clearly defined. It is possible that GLRA4 is dysregulated in patients 1 and 3 due to a position effect, in case their centromeric breakpoints do not affect GLRA4. Our patient DGDP084 without the deletion of PLP1 displays clinical features including intellectual disability, speech delay, and craniofacial anomalies which are also present in the patient of Torisu as a result of PLP1 deletion (Table 1). Interestingly, patients displayed a wider range of clinical features when GLRA4 is included in the Xq22.2 microdeletion. In the case of
DGDP084, the phenotype was more severe compared to other patients.

The fourth transmembrane domain (TM4) is conserved among several species except human

Amino acid residues of GLRA4 are evolutionarily conserved throughout the seven mammalian species. Only human GLRA4 (NP_001019623.2) shows an absence of 40 amino acids at the C-terminal region, part of which codes for the fourth transmembrane domain TM4 (Fig. 7) [11]. The amino acid sequence of the TM4 domain is highly conserved among other species.

\section{Discussion}

The Xq22.2 region harbors PLP1 causative for PelizaeusMerzbacher disease characterized by cognitive impairment, 


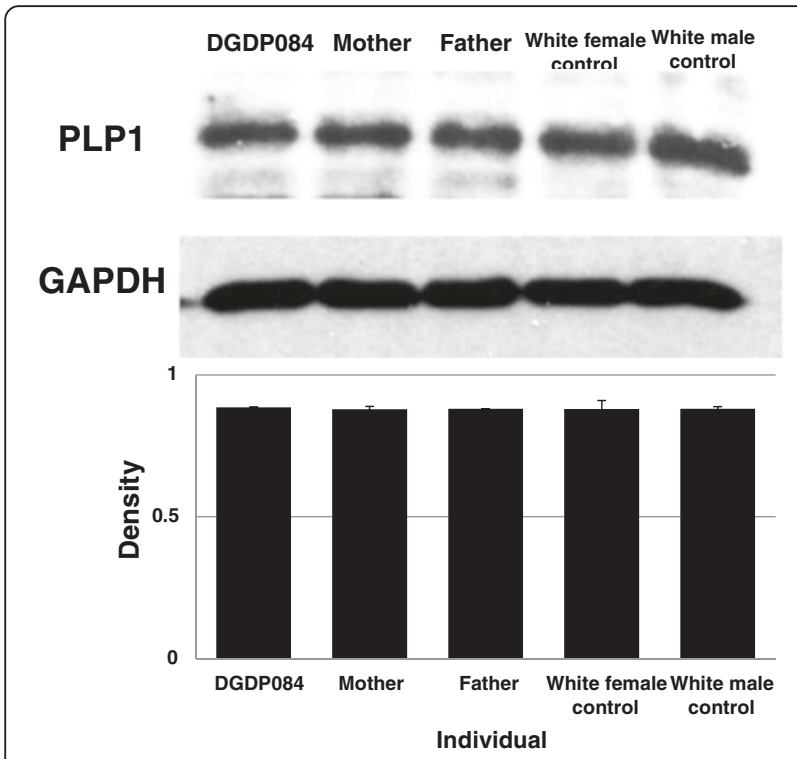

Fig. 6 Western blot showing PLP1 expression levels in DGDP084 and her family members. The protein level of PLP1 in the patient was similar to her parents as well as the white female and male controls. GAPDH protein levels were used as a reference for densitometry analysis

severe spasticity, hypotonia, nystagmus and ataxia [12]. Most of the CNVs in this interval include PLP1 and neighboring genes, suggesting the occurrence of microdeletion and microduplication syndromes at Xq22.2 with phenotypic features including intellectual disability (ID), behavioral abnormalities, and hypotonia [8]. The patient DGDP084 investigated in the present study displays intellectual disability, behavioral problems, and craniofacial anomalies. She has a de novo Xq22.2 microdeletion of at least $110 \mathrm{~Kb}$ encompassing only three annotated genes namely, MORF4L2 and TCEAL1 as well as an apparent human pseudogene GLRA4 [11, 14, 15]. Both microarray and qPCR (Fig. 3) show that PLP1 located immediately distal to GLRA4 is not deleted (Fig. 2). Moreover, DGDP084 did not display anomalies in myelination, and the brain scan (MRI) performed was normal, making it highly unlikely that PLP1 is the underlying cause of the clinical features. This is substantiated by Western blot showing similar levels of PLP1 expression in DGDP084 and her parents (Fig. 6), suggesting this gene is not dysregulated by a position effect. The cytogenetic band of Xq22.2 with a large interval of $1 \mathrm{Mb}$ containing at least 21 annotated genes suggests the presence of one or more XLID genes in this region. So far, PLP1 is the only gene known to be involved in XLID, and importantly, this is the first case of microdeletion with syndromic intellectual disability at Xq22.2 without involvement of PLP1. Conspicuously, the transcript levels of GLRA4 were significantly reduced in DGDP084 compared to her healthy mother and this is consistent with the random $\mathrm{X}$ inactivation result suggesting chromosome $\mathrm{X}$ with the $\mathrm{Xq} 22.2$ microdeletion is not preferentially inactivated. The higher dosage of GLRA4 in the healthy mother compared to her healthy husband suggests that females express higher levels of GLRA4 compared to males by either escaping Xinactivation or incomplete silencing of the inactive $\mathrm{X}$ chromosome occurred in this family. Notably, MORF4L2 and TCEAL1 transcripts were expressed at similar levels in the patient and her parents. The transcript levels of GLRA4, MORF4L2 and TCEAL1 were significantly higher in the whole human brain and fetal brain compared to other tissues such as heart, liver and kidney (Fig. 5a-c). High level of transcripts of all three genes were detected in various areas of the brain including the cerebellum and hippocampus (Fig. 5d-f), regions of the brain known to be associated with learning and memory [30]. The reduction of GLRA4 transcript levels in DGDP084 in the family coupled with its expression pattern in the brain suggest that GLRA4 is the plausible candidate gene for the clinical features observed in DGDP084 including intellectual disability, behavioral abnormalities, and craniofacial anomalies. Interestingly, the phenotype observed as a result of the microdeletion in DGDP084 shows overlap with the clinical features produced as a result of PLP1 disruption including cognitive impairment and motor delay $[8,31]$ suggesting that both

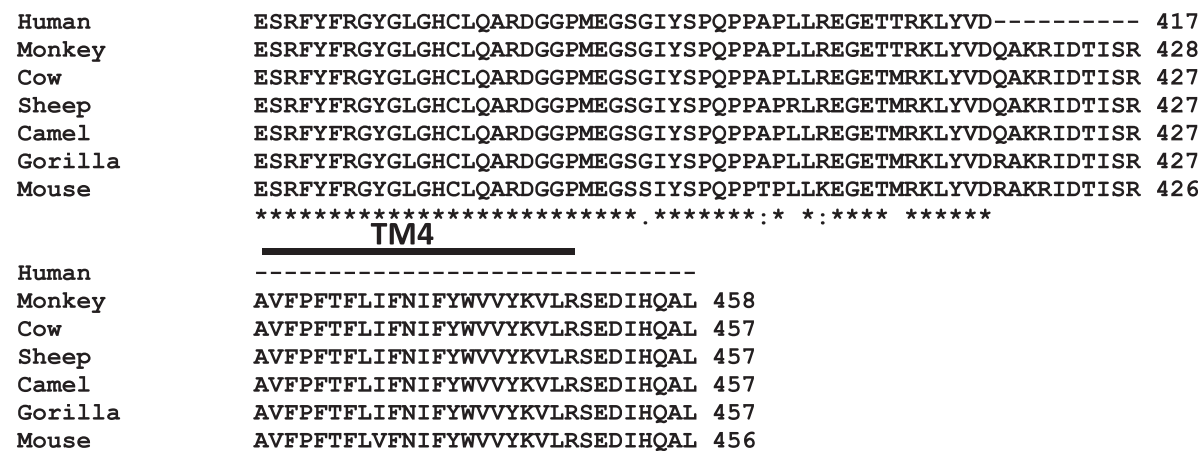

Fig. 7 GLRA4 C-terminal end amino acid alignment across seven species including mouse, human, gorilla, monkey, camel, sheep and cow. The last 90 amino acids are displayed along with the location of the TM4 domain. Human GLRA4 is the only species missing the conserved TM4 domain 
genes, physically located in close proximity, may participate in similar molecular function.

Comparable levels of TCEAL1 and MORF4L2 transcripts were detected in DGDP084 and her parents (Fig. 4b and c). This means that even if their high level of expression in the human brain and skeletal muscle (Fig. 5b and c) suggests a role in neurological and motor function, these genes may be excluded as contributing to cognitive impairment, behavioral abnormalities and craniofacial anomalies. Additional point mutations or intragenic deletions of GLRA4 and functional studies are required to support our hypothesis. It is interesting to note that TCEAL1 has been shown to interact with PTPN11 [32], the causative gene for Noonan syndrome characterized by short stature, craniofacial anomalies, pectus deformities, webbed neck and sometimes ID [33, 34]. Moreover, Mrgx, the mouse orthologue of MORF4L2 (aka MRGX, MIM 300409) has been shown to interact with HNRNPK [35], a gene known to be associated cognitive impairment [36]. However, knockout of Mgrx does not affect mouse development as the mice remain healthy and fertile [37].

Glycine receptor chloride channels (GLR) are pentameric proteins belonging to the Cys-loop family of ligandgated ion channel receptors [14]. A total of five glycine receptor chloride channel subunit genes exist in humans, and these channels are usually composed of homoor hetero-pentamers arranged around a central ionconducting pore [38]. Functional homomeric $\alpha$-GLRs have been shown to be assembled in the human embryonic kidney HEK-293 cell line [39], and their activation mechanisms have been studied in rat [40]. Most GLRs are assembled from four $\alpha$-subunits (GLRA1, GLRA2, GLRA3 and GLRA4) and one $\beta$-subunit (GLRB) [15, 41, 42]. Each subunit has an extracellular domain containing the neurotransmitter binding site, and a transmembrane domain comprising four transmembrane $\alpha$-helices (TM1-TM4) connected by flexible loops [43]. The $\alpha$ subunits show a high degree of amino acid identity [44] indicating that they evolved by gene duplication [16, 45]. Being a transmembrane protein, GLRs selectively allow passage of $\mathrm{Cl}^{-}$ ions when glycine binds at specific sites on the receptor surface $[41,46]$. GLRs are important in mediating inhibitory neurotransmission in a number of regions of the brain including mammalian brainstem and spinal cord where they are widely expressed [14, 16, 17]. Through electron microscopy, it has been shown that in rats GLRs are tightly packed around presynaptic terminals at central synapses $[41,46]$. The functional importance of GLRs and the observed patterns of expression of GLRA4 in the brain are consistent with a role in cognitive deficits and behavioral abnormalities observed in patient DGDP084.

Previously, it has been shown that mutations in the $\alpha 1$ subunit of glycine receptor (GLRA1) are responsible for the neurological disorder hyperekplexia (MIM 149400) characterized by muscle rigidity originating from the CNS as well as an exaggerated startle response [47]. Sudden muscle contractions are often observed in infancy and can sometimes lead to death possibly due to apnea or aspiration $[48,49]$. Interestingly, a male patient possessing both missense and splice site mutations in $G L R B$, a $\beta$-subunit of the pentameric GLRs, has been reported to display hyperekplexia [50]. This shows that subtle alterations in the structure of GLRs can affect functioning of this ligand-gated ion channel in the brain. Our patient DGDP084 does not have hyperekplexia and it is possible that the cognitive impairment and unusual behaviors displayed by DGDP084 such as banging on windows and furniture may be due to reduced GLRA4 expression in the brain disrupting the composition of heteromeric GLRs. It is interesting to note that patients with hyperekplexia display delay in speech acquisition and ID which usually normalize in infancy $[43,51]$.

In humans, the role of GLRA4 in the functioning of GLRs is unclear because of the stop codon in exon 9 upstream of the predicted TM4 domain common in the three other human $\alpha$ subunits [11]. The sequence of each of the three GLR genes ( $\alpha 1-\alpha 3$; GLRA1, GLRA2, GLRA3) encodes four TM domains which act as important barriers between the ion permeation pathway and the apolar areas of the lipid bilayer [41]. The absence of the TM4 domain in GLRA4 is thought to produce an inactive protein [11, $14,15]$. Interestingly, a recent study has shown that GLRA1 subunits with a recessive mutation p.E375X truncating upstream of TM4 domain are incorporated into functional pentametric GLRs and retain glycine sensitivity [43]. We propose the human GLRA4 protein lacking TM4 is not a pseudogene, but is required for the assembly and stability of some heteromeric GLRs. This is also substantiated by high levels of GLRA4 transcripts detected in various part of the human brain including the cerebellum and hippocampus. Furthermore, we cannot exclude the possibility that GLRA4 transcripts may also play a regulatory role in the brain by modulating transcription of other GLR genes through RNAi due to its high sequence homology with GLRA1, GLRA2 and GLRA3.

Pseudogenes have previously been shown to have regulatory functions [20-22] and may play a role in health and disease $[19,21]$. For instance, pseudogenes of cancerrelated genes have previously been shown to have regulatory roles in tumor biology [21] and type 2 diabetes [22] by modulating the levels of their corresponding functional gene through posttranscriptional silencing. Our hypotheses are also in agreement with a study on the $\gamma$-aminobutyric acid type $A\left(G_{A B A}\right)$ where alternative splice variants of the $\mathrm{GABA}_{\mathrm{A}} \alpha 4$ (including one variant that lacks exon 9 which encodes the TM4 domain), are thought to have a posttranslational regulatory role $[11,54]$. GABA $A_{A}$ receptors 
are also chloride-gated ion channel receptors playing important roles as inhibitory neurotransmitter receptors in the brain $[11,54,55]$.

\section{Conclusion}

The clinical features displayed by DGDP084 are consistent with a neurological dysfunction arising as a result of the Xq22.2 microdeletion. Our comparative deletion mapping and RT-qPCR results support the hypothesis that GLRA4 is a novel candidate gene for XLID and is likely involved in the intellectual disability, behavioral problems, and craniofacial anomalies seen in DGDP084. Additional point mutations or intragenic deletions of GLRA4 are required to further substantiate our hypothesis.

\section{Additional file}

Additional file 1: Table S1. Primers used for $q P C R$ and RT-qPCR. Table S2. Numerical means and standard deviations of $\mathrm{GPCR}$ and RT-qPCR on family members. Table S3. Numerical means and standard deviations of RT-qPCR on human tissues. (DOCX $17 \mathrm{~kb}$ )

\section{Abbreviations}

aCGH, array comparative genomic hybridization; CNS, central nervous system; CNVs, copy number variations; EEG, electroencephalogram; GABA Y-aminobutyric acid type A; GAPDH, glyceraldehyde-3-phosphate dehydrogenase; GLRA1, glycine receptor, alpha-1 subunit; GLRA2, glycine receptor, alpha-2 subunit; GLRA3, glycine receptor, alpha-3 subunit; GLRA4, glycine receptor, alpha-4 subunit; GLRB, glycine receptor, beta subunit; GLRs, glycine receptors; HMGA1, high mobility group at-hook 1; ID, intellectual disability; MORF4L2, mortality factor 4-like protein 2; MRGX, morf-related gene $x ; P L P 1$, proteolipid protein 1; PMD, Pelizaeus-Merzbacher disease; PTEN, phosphatase and tensin homolog; PTENP1, phosphatase and tensin homolog pseudogene 1; PTPN11, protein-tyrosine phosphatase, nonreceptor-type, 11; qPCR, quantitative polymerase chain reaction; $R A B 9 B$, ras-associated protein 9b; RT-qPCR, reverse-transcriptase quantitative polymerase chain reaction; TCEAL1, transcription elongation factor a-like 1; TCEAL3, transcription elongation factor a-like 3; TM4, 4th transmembrane domain; $\mathrm{XCl}, \mathrm{X}$ chromosome inactivation; XLID, X-linked intellectual disability

\section{Acknowledgements}

We would like to that the family who kindly consented to participate in our genetics study. We also wish to extend our thanks to Lynn Chorich for managing the database and cell repository.

We acknowledge with gratitude the support of funding provided by Caroline Jones-Carrick and Collin Carrick.

\section{Availability of data and materials}

The genomic coordinates of $105 \mathrm{~kb}$ minimal and $145 \mathrm{~kb}$ maximal microdeletion at Xq22.2 detected by microarray analysis in our patient DGDP084 were described in the Results section.

\section{Authors' contributions \\ $J \mathrm{~L}$ generated data for refining of breakpoints, examining of transcript levels, comparative deletion mapping and wrote the manuscript. HGK conceived the project, analyzed and interpreted the data of comparative deletion mapping, and wrote the manuscript. TG performed Western Blot on PLP1, while microarray was carried out by YS. X-inactivation data was produced by JJ. LL and IKK contributed to data interpretation and reviewed the manuscript. All authors read and approved the final manuscript.}

\section{Competing interests}

The authors declare that they have no competing interests.

\section{Ethics approval and consent to participate}

This study was approved by the Institutional Review Board of Augusta University and written informed consent was obtained from the mother of DGDP084 for the publication of this report and accompanying images.

\section{Author details}

'Department of Obstetrics \& Gynecology, Section of Reproductive Endocrinology, Infertility \& Genetics, Medical College of Georgia, Augusta University, 1120 15th Street, Augusta, GA 30912, USA. ²Department of Neuroscience and Regenerative Medicine, Medical College of Georgia, Augusta University, 1120 15th Street, Augusta, GA 30912, USA. ${ }^{3}$ Department of Laboratory Medicine, Boston Children's Hospital, Harvard Medical School, Boston, MA 02115, USA. ${ }^{4}$ Greenwood Genetic Center, Greenwood, SC 29646, USA. ${ }^{5}$ Department of Animal Science, Division of Applied Life Science (BK21plus), Institute of Agriculture and Life Science, Gyeongsang National University, Jinju, Gyeongsangnam-do, South Korea. 'Neuroscience Program, Medical College of Georgia, Augusta University, Augusta, GA 30912, USA.

Received: 29 April 2016 Accepted: 20 July 2016

Published online: 09 August 2016

\section{References}

1. Ropers HH. X-linked mental retardation: many genes for a complex disorder Curr Opin Genet Dev. 2006;16(3):260-9.

2. Hu H, Haas SA, Chelly J, Van Esch H, Raynaud M, de Brouwer AP, Weinert S, Froyen G, Frints SG, Laumonnier F, et al. X-exome sequencing of 405 unresolved families identifies seven novel intellectual disability genes. Mol Psychiatry. 2016;21(1):133-48.

3. Ropers HH, Hamel BC. X-linked mental retardation. Nat Rev Genet. 2005;6(1): 46-57.

4. Deng X, Berletch JB, Nguyen DK, Disteche CM. X chromosome regulation: diverse patterns in development, tissues and disease. Nat Rev Genet. 2014;15(6):367-78.

5. Ross MT, Grafham DV, Coffey AJ, Scherer S, McLay K, Muzny D, Platzer M, Howell GR, Burrows C, Bird CP, et al. The DNA sequence of the human $X$ chromosome. Nature. 2005;434(7031):325-37.

6. Laumonnier F, Bonnet-Brilhault F, Gomot M, Blanc R, David A, Moizard MP, Raynaud M, Ronce N, Lemonnier E, Calvas P, et al. X-linked mental retardation and autism are associated with a mutation in the NLGN4 gene, a member of the neuroligin family. Am J Hum Genet. 2004;74(3):552-7.

7. Vincent JB, Kolozsvari D, Roberts WS, Bolton PF, Gurling HM, Scherer SW. Mutation screening of X-chromosomal neuroligin genes: no mutations in 196 autism probands. Am J Med Genet B Neuropsychiatr Genet. 2004;129B(1):82-4.

8. Yamamoto T, Wilsdon A, Joss S, Isidor B, Erlandsson A, Suri M, Sangu N, Shimada S, Shimojima K, Le Caignec C, et al. An emerging phenotype of Xq22 microdeletions in females with severe intellectual disability, hypotonia and behavioral abnormalities. J Hum Genet. 2014;59(6):300-6.

9. Ahmed I, Rafiq MA, Vincent JB, Bhatti A, Ayub M, John P. Homozygosity mapping of autosomal recessive intellectual disability loci in 11 consanguineous Pakistani families. Acta Neuropsychiatr. 2015;27(1):38-47.

10. Zhou S, Shi Z, Cui M, Li J, Ma Z, Shi Y, Zheng Z, Zhang F, Jin T, Geng T, et al. A New Role for LOC101928437 in Non-Syndromic Intellectual Disability: Findings from a Family-Based Association Test. PLoS One. 2015;10(8), e0135669.

11. Simon J, Wakimoto H, Fujita N, Lalande M, Barnard EA. Analysis of the set of GABA(A) receptor genes in the human genome. J Biol Chem. 2004;279(40): 41422-35.

12. Woodward K, Kendall E, Vetrie D, Malcolm S. Pelizaeus-Merzbacher disease: identification of Xq22 proteolipid-protein duplications and characterization of breakpoints by interphase FISH. Am J Hum Genet. 1998;63(1):207-17.

13. Stevenson RE, Tarpey P, May MM, Stratton MR, Schwartz CE. Arena syndrome is caused by a missense mutation in PLP1. Am J Med Genet A. 2009;149A(5):1081.

14. Lynch JW. Native glycine receptor subtypes and their physiological roles. Neuropharmacology. 2009;56(1):303-9.

15. Bode A, Lynch JW. The impact of human hyperekplexia mutations on glycine receptor structure and function. Mol Brain. 2014;7:2.

16. Matzenbach B, Maulet $Y$, Sefton L, Courtier B, Avner P, Guenet JL, Betz H. Structural analysis of mouse glycine receptor alpha subunit genes. 
Identification and chromosomal localization of a novel variant. J Biol Chem. 1994;269(4):2607-12.

17. Baer K, Waldvogel HJ, Faull RL, Rees MI. Localization of glycine receptors in the human forebrain, brainstem, and cervical spinal cord: an immunohistochemical review. Front Mol Neurosci. 2009;2:25.

18. Zhang Z, Gerstein M. Large-scale analysis of pseudogenes in the human genome. Curr Opin Genet Dev. 2004;14(4):328-35.

19. Pink RC, Wicks K, Caley DP, Punch EK, Jacobs L, Carter DR. Pseudogenes: pseudo-functional or key regulators in health and disease? RNA. 2011;17(5): 792-8.

20. Tam OH, Aravin AA, Stein P, Girard A, Murchison EP, Cheloufi S, Hodges E, Anger M, Sachidanandam R, Schultz RM, et al. Pseudogene-derived small interfering RNAs regulate gene expression in mouse oocytes. Nature. 2008;453(7194):534-8.

21. Poliseno L, Salmena L, Zhang J, Carver B, Haveman WJ, Pandolfi PP. A coding-independent function of gene and pseudogene mRNAs regulates tumour biology. Nature. 2010;465(7301):1033-8.

22. Chiefari E, liritano S, Paonessa F, Le Pera I, Arcidiacono B, Filocamo M, Foti D, Liebhaber SA, Brunetti A. Pseudogene-mediated posttranscriptional silencing of HMGA1 can result in insulin resistance and type 2 diabetes. Nat Commun. 2010;1:40

23. Nishimoto HK, Ha K, Jones JR, Dwivedi A, Cho HM, Layman LC, Kim HG. The historical Coffin-Lowry syndrome family revisited: identification of two novel mutations of RPS6KA3 in three male patients. Am J Med Genet A. 2014; 164A(9):2172-9.

24. Miller DT, Shen Y, Wu BL. Oligonucleotide microarrays for clinical diagnosis of copy number variation and zygosity status. Curr Protoc Hum Genet. 2012;Chapter 8:Unit8 12.

25. Allen RC, Zoghbi HY, Moseley AB, Rosenblatt HM, Belmont JW. Methylation of Hpall and Hhal sites near the polymorphic CAG repeat in the human androgen-receptor gene correlates with $\mathrm{X}$ chromosome inactivation. Am J Hum Genet. 1992:51(6):1229-39.

26. Labonne JD, Chung MJ, Jones JR, Anand P, Wenzel W, lacoboni D, Layman LC, Kim HG. Concomitant partial exon skipping by a unique missense mutation of RPS6KA3 causes Coffin-Lowry syndrome. Gene. 2016;575(1):42-7.

27. Matsufuji M, Osaka H, Gotoh L, Shimbo H, Takashima S, Inoue K. Partial PLP1 deletion causing $X$-linked dominant spastic paraplegia type 2. Pediatr Neurol. 2013:49(6):477-81.

28. Torisu H, Iwaki A, Takeshita K, Hiwatashi A, Sanefuji M, Fukumaki Y, Hara T. Clinical and genetic characterization of a 2-year-old boy with complete PLP1 deletion. Brain Dev. 2012;34(10):852-6.

29. Inoue K, Osaka H, Thurston VC, Clarke JT, Yoneyama A, Rosenbarker L, Bird TD, Hodes ME, Shaffer LG, Lupski JR. Genomic rearrangements resulting in PLP1 deletion occur by nonhomologous end joining and cause different dysmyelinating phenotypes in males and females. Am J Hum Genet. 2002;71(4):838-53.

30. Bliss TV, Collingridge GL. A synaptic model of memory: long-term potentiation in the hippocampus. Nature. 1993;361 (6407):31-9.

31. Grossi S, Regis S, Biancheri R, Mort M, Lualdi S, Bertini E, Uziel G, Boespflug Tanguy O, Simonati A, Corsolini F, et al. Molecular genetic analysis of the PLP1 gene in 38 families with PLP1-related disorders: identification and functional characterization of 11 novel PLP1 mutations. Orphanet J Rare Dis. 2011;6:40.

32. Elia AE, Boardman AP, Wang DC, Huttlin EL, Everley RA, Dephoure N, Zhou C, Koren I, Gygi SP, Elledge SJ. Quantitative Proteomic Atlas of Ubiquitination and Acetylation in the DNA Damage Response. Mol Cell. 2015;59(5):867-81.

33. Tartaglia M, Mehler EL, Goldberg R, Zampino G, Brunner HG, Kremer H, van der Burgt I, Crosby AH, lon A, Jeffery S, et al. Mutations in PTPN11, encoding the protein tyrosine phosphatase SHP-2, cause Noonan syndrome. Nat Genet. 2001;29(4):465-8.

34. Gelb BD, Tartaglia M. Noonan syndrome and related disorders: dysregulated RAS-mitogen activated protein kinase signal transduction. Hum Mol Genet. 2006:15 Spec No 2:R220-6.

35. Hayakawa T, Ohtani Y, Hayakawa N, Shinmyozu K, Saito M, Ishikawa F, Nakayama J. RBP2 is an MRG15 complex component and down-regulates intragenic histone H3 lysine 4 methylation. Genes Cells. 2007;12(6):811-26.

36. Au PY, You J, Caluseriu O, Schwartzentruber J, Majewski J, Bernier FP, Ferguson M, Valle D, Parboosingh JS, Sobreira N, et al. GeneMatcher aids in the identification of a new malformation syndrome with intellectual disability, unique facial dysmorphisms, and skeletal and connective tissue abnormalities caused by de novo variants in HNRNPK. Hum Mutat. 2015:36(10):1009-14

37. Tominaga K, Matzuk MM, Pereira-Smith OM. MrgX is not essential for cell growth and development in the mouse. Mol Cell Biol. 2005;25(12):4873-80.

38. Corringer PJ, Baaden M, Bocquet N, Delarue M, Dufresne V, Nury H, Prevost $\mathrm{M}$, Van Renterghem C. Atomic structure and dynamics of pentameric ligand-gated ion channels: new insight from bacterial homologues. J Physiol. 2010;588(Pt 4):565-72.

39. De Saint JD, David-Watine B, Korn H, Bregestovski P. Activation of human alpha1 and alpha2 homomeric glycine receptors by taurine and GABA. J Physiol. 2001;535(Pt 3):741-55.

40. Beato M, Groot-Kormelink PJ, Colquhoun D, Sivilotti LG. The activation mechanism of alpha1 homomeric glycine receptors. J Neurosci. 2004;24(4): 895-906.

41. Lynch JW. Molecular structure and function of the glycine receptor chloride channel. Physiol Rev. 2004;84(4):1051-95.

42. Mowrey DD, Cui T, Jia Y, Ma D, Makhov AM, Zhang P, Tang P, Xu Y. Openchannel structures of the human glycine receptor alpha1 full-length transmembrane domain. Structure. 2013;21(10):1897-904.

43. Bode A, Wood SE, Mullins JG, Keramidas A, Cushion TD, Thomas RH, Pickrell WO, Drew CJ, Masri A, Jones EA, et al. New hyperekplexia mutations provide insight into glycine receptor assembly, trafficking, and activation mechanisms. J Biol Chem. 2013;288(47):33745-59.

44. Rajendra S, Lynch JW, Schofield PR. The glycine receptor. Pharmacol Ther. 1997;73(2):121-46.

45. Grenningloh G, Rienitz A, Schmitt B, Methfessel C, Zensen M, Beyreuther K, Gundelfinger ED, Betz $H$. The strychnine-binding subunit of the glycine receptor shows homology with nicotinic acetylcholine receptors. Nature. 1987;328(6127):215-20.

46. Triller A, Cluzeaud F, Pfeiffer F, Betz H, Korn H. Distribution of glycine receptors at central synapses: an immunoelectron microscopy study. J Cell Biol. 1985;101(2):683-8

47. Shiang R, Ryan SG, Zhu YZ, Hahn AF, O'Connell P, Wasmuth JJ. Mutations in the alpha 1 subunit of the inhibitory glycine receptor cause the dominant neurologic disorder, hyperekplexia. Nat Genet. 1993;5(4):351-8.

48. Nigro MA, Lim HC. Hyperekplexia and sudden neonatal death. Pediatr Neurol. 1992:8(3):221-5.

49. Giacoia GP, Ryan SG. Hyperekplexia associated with apnea and sudden infant death syndrome. Arch Pediatr Adolesc Med. 1994;148(5):540-3.

50. Rees MI, Lewis TM, Kwok JB, Mortier GR, Govaert P, Snell RG, Schofield PR, Owen MJ. Hyperekplexia associated with compound heterozygote mutations in the beta-subunit of the human inhibitory glycine receptor (GLRB). Hum Mol Genet. 2002;11(7):853-60.

51. Al-Futaisi AM, Al-Kindi MN, Al-Mawali AM, Koul RL, Al-Adawi S, Al-Yahyaee SA. Novel mutation of GLRA1 in Omani families with hyperekplexia and mild mental retardation. Pediatr Neurol. 2012:46(2):89-93.

52. Bertram MJ, Berube NG, Hang-Swanson X, Ran Q, Leung JK, Bryce S, Spurgers K, Bick RJ, Baldini A, Ning Y, et al. Identification of a gene that reverses the immortal phenotype of a subset of cells and is a member of a novel family of transcription factor-like genes. Mol Cell Biol. 1999;19(2):1479-85.

53. Pillutla RC, Shimamoto A, Furuichi Y, Shatkin AJ. Genomic structure and chromosomal localization of TCEAL1, a human gene encoding the nuclear phosphoprotein p21/SIIR. Genomics. 1999;56(2):217-20.

54. Mu W, Cheng Q, Yang J, Burt DR. Alternative splicing of the GABA(A) receptor alpha 4 subunit creates a severely truncated mRNA. Brain Res Bull. 2002;58(5):447-54.

55. James OT, Livesey MR, Qiu J, Dando O, Bilican B, Haghi G, et al. Ionotropic GABA and glycine receptor subunit composition in human pluripotent stem cell-derived excitatory cortical neurones. J Physiol. 2014;592(Pt19):4353-63. 